\title{
Características da EPIDERMe Foliar de Eucalipto E SEU ENVOLVIMENTO COM A TOLERÂNCIA AO GLYPHOSATE ${ }^{1}$
}

\author{
Characteristics of Eucalypt Leaf Epidermis and its Role in Glyphosate Tolerance
}

TUFFI SANTOS, L.D. ${ }^{2}$, IAREMA, L. ${ }^{3}$, THADEO, M. ${ }^{3}$, FERREIRA, F.A. ${ }^{4}$ e MEIRA, R.M.S.A. ${ }^{5}$

\begin{abstract}
RESUMO - Em áreas de reflorestamento, a deriva do glyphosate causa injúrias nas plantas de eucalipto. Trabalhos preliminares de pesquisa e observações de campo apontam para uma tolerância diferencial ao glyphosate entre os genótipos cultivados. Nesse contexto, objetivouse estudar as estruturas anatômicas da epiderme foliar de cinco espécies de eucalipto, correlacionando com a tolerância ao glyphosate em deriva simulada. Utilizou-se o esquema fatorial, sendo cinco espécies (Eucalyptus urophylla, E. grandis, E. pellita, E. resinifera e E. saligna) e cinco subdoses $\left(0 ; 43,2 ; 86,4 ; 172,8\right.$ e 345,6 g e.a. ha ${ }^{-1}$ de glyphosate), simulando uma deriva. Imediatamente antes da aplicação do herbicida, coletaram-se folhas, totalmente expandidas, para análise anatômica da superfície epidérmica segundo metodologia de dissociação. Entre as espécies estudadas, E. resinifera mostrou-se mais tolerante à deriva de glyphosate, apresentando os menores valores de porcentagem de intoxicação aos 45 dias após aplicação, não sendo encontrada diferença entre as demais espécies. As cinco espécies apresentam folhas glabras, anfiestomáticas, com estômatos do tipo anomocítico e cutícula proeminente. Apesar de presentes em ambas as faces, os estômatos são raros na face adaxial, apresentando baixo índice e densidade estomática. Os maiores valores para índice estomático foram observados em E. resinifera, enquanto $E$. saligna apresentou a maior densidade estomática. Cavidades subepidérmicas evidenciadas na superfície pelas células de cobertura estão presentes nas cinco espécies, com maior densidade em E. pellita. Houve alta correlação entre a porcentagem de intoxicação por glyphosate e o número de células epidérmicas da superfície adaxial, indicando envolvimento desta característica com a tolerância diferencial ao herbicida. Estudos sobre absorção, translocação e metabolismo do glyphosate em eucalipto devem ser realizados para elucidar o comportamento diferencial de genótipos diante da deriva de glyphosate.
\end{abstract}

Palavras-chave: Eucalyptus spp., anatomia, herbicida, deriva simulada, fitotoxidez.

ABSTRACT - In reforestation areas, glyphosate drift causes injuries in Eucalyptus plants. Preliminary research work and field observations point out a differential tolerance to glyphosate among cultivated genotypes. Within this context, the anatomical structures of leaf epidermis of five species of eucalypt, correlated to glyphosate tolerance under simulated drift were studied. The factorial design was used, with the species (Eucalyptus urophylla, E. grandis, E. pellita,

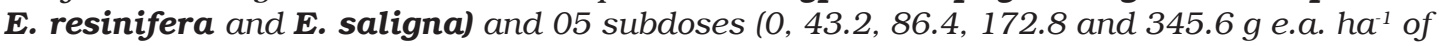
glyphosate) simulating a drift. Immediately before herbicide application, totally expanded leaves were collected for anatomical analysis of epidermal surface through dissociation methodology. Among the studied species, E. resinifera was found to be the most tolerant to glyphosate drift, presenting the lowest values for intoxication percentage 45 days post-application, with no difference among the others. The five species present glabrous, amphistomatic leaves with anomocytic type stomata and prominent cuticle. Despite being present on both faces, stomata are rare on the adaxial face, exhibiting low index and stomatic density. The highest values for

Recebido para publicação em 3.4.2006 e na forma revisada em 4.8.2006.

2 Doutorando em Fitotecnia, Departamento de Fitotecnia, Universidade Federal de Viçosa - DFT/UFV, 36570-000 Viçosa-MG, Bolsista do CNPq, <ltuffi@ yahoo.com.br>; ${ }^{3}$ Doutoranda em Botânica - DBV/UFV, Bolsista da Capes; ${ }^{4}$ Professor Titular do Departamento de Fitotecnia - DFT/UFV; ${ }^{5}$ Professora Adjunta do Departamento de Biologia Vegetal - DBV/UFV.

Planta Daninha, Viçosa-MG, v. 24, n. 3, p. 513-520, 2006 
stomatic index were observed on $\boldsymbol{E}$. resinifera, while $\boldsymbol{E}$. saligna presented the highest stomatic density. Subepidermic cavities evidenced on the surface by the overlying cells are present in the five species, with the highest density on $\boldsymbol{E}$. pellita. A high correlation was found between intoxication percentage and number of epidermic cells on the adaxial surface, indicating the involvement of this characteristic with differential tolerance to the herbicide. Studies on absorption, translocation and metabolism of glyphosate in eucalypt must be undertaken to elucidate the differential behaviour of genotypes concerning glyphosate drift.

Keywords: Eucalyptus spp., anatomy, herbicide, simulated drift, phytotoxicity.

\section{INTRODUÇÃO}

O manejo de plantas daninhas destaca-se dentre as principais práticas silviculturais em lavouras de eucalipto. Essa prática se intensifica no período das chuvas, principalmente nos primeiros anos de implantação, sendo feito basicamente por métodos de controle químico e mecânico, isolados ou combinados (Toledo, 2003). Entre os herbicidas usados, o glyphosate tem se destacado, por ser aplicado na fase de pós-emergência das plantas daninhas, o que favorece operações em áreas de cultivo mínimo; além disso, exerce efetivo controle de grande número de espécies daninhas mono e dicotiledôneas, perenes e anuais, sendo um herbicida de curto período residual e rapidamente inativado no solo (Malik et al., 1989).

Em áreas onde o controle químico é adotado, o contato da molécula herbicida com organismos não-alvo - o que caracteriza o problema da deriva - tem sido relatado com freqüência. Em aplicações dirigidas de produtos não-seletivos, como no caso dos herbicidas à base de glyphosate, a própria cultura pode ser afetada pela deriva.

Relatos de pessoas ligadas ao manejo florestal e observações de campo nas empresas do setor apontam para uma diferença de tolerância ao glyphosate entre os genótipos cultivados. Em trabalho com deriva simulada de glyphosate em eucalipto, Tuffi Santos et al. (2006) relataram comportamento diferencial entre diferentes clones, sendo Eucalyptus grandis mais suscetivel e E. urophylla mais tolerante. Entretanto, os mecanismos envolvidos nesta tolerância diferencial não são esclarecidos.
A literatura (Sandberg et al., 1980; D'Anieri et al., 1990; Satichivi et al., 2000; Monquero et al., 2004) demonstra que a tolerância de plantas ao glyphosate ocorre devido à penetração ou translocação diferencial deste herbicida na planta. As taxas de absorção foliar de herbicidas e, conseqüentemente, sua eficácia estão diretamente ligadas aos tipos de estruturas encontradas na folha e à permeabilidade da cutícula (Baker, 1982), que por sua vez depende da constituição e da polaridade desta. Estudos demonstram que nos estômatos e na base dos tricomas a cutícula é mais fina e mais permeável a substâncias polares (menor teor de cera epicuticular), sendo uma via de penetração de herbicidas (Hess \& Falk, 1990; Schreiber, 2005). Esse fato pode favorecer a penetração do glyphosate em plantas onde a presença dessas estruturas epidérmicas seja freqüente.

Diante do exposto, objetivou-se estudar as estruturas anatômicas da epiderme foliar de cinco espécies de eucalipto, correlacionando com a tolerância diferencial ao glyphosate em deriva simulada.

\section{MATERIAL E MÉTODOS}

O experimento foi realizado em casa de vegetação pertencente ao Departamento de Fitotecnia da Universidade Federal de Viçosa, entre os meses de dezembro de 2004 e fevereiro de 2005.

Mudas padronizadas de Eucalyptus grandis, E. urophylla, E. saligna, E. pellita e E. resinifera, oriundas de semente, com aproximadamente $30 \mathrm{~cm}$ de altura e 3 meses de idade, foram plantadas em vasos preenchidos com 10 L de solo argiloso, adubado com 216,6 g de N-P-K (6-30-6) e 12 g de calcário, cuja 
proporção $\mathrm{Ca} / \mathrm{Mg}$ era de 4:1 equivalentes. A adubação de cobertura foi feita com $12 \mathrm{~g}$ por vaso de N-P-K (20-5-20), parcelado em três vezes. As plantas foram mantidas em casa de vegetação, recebendo irrigação por microaspersão de modo a manter adequada a disponibilidade de água.

Utilizou-se o delineamento em blocos casualizados, com quatro repetições, sendo cada vaso considerado uma parcela experimental. $\mathrm{O}$ ensaio foi montado em esquema fatorial $5 \mathrm{x}$ 5 (sendo cinco espécies de eucalipto e cinco doses de glyphosate). As doses testadas foram de $0 ; 43,2 ; 86,4 ; 172,8$; e 345,6 g e.a. ha ${ }^{-1}$ de glyphosate, respectivamente correspondentes a $0,3,6,12$ e $24 \%$ da dose de 1.440 g e.a. ha-1 da formulação sal de isopropilamina. Os tratamentos foram aplicados 40 dias após o plantio das mudas, quando as plantas de eucalipto apresentavam cerca de $45 \mathrm{~cm}$ de altura, diretamente sobre as plantas, simulando uma deriva, de modo que não atingisse o terço superior destas. Na aplicação, utilizou-se pulverizador costal de precisão, munido de barra com dois bicos com pontas do tipo leque TT110.02 espaçadas de $0,5 \mathrm{~m}$, operando a $250 \mathrm{kPa}$ de pressão, trabalhando com volume de calda correspondente a $200 \mathrm{~L} \mathrm{ha}^{-1}$. No momento da aplicação do glyphosate a umidade relativa do ar encontrava-se a $85 \%$, a temperatura era de $26,5{ }^{\circ} \mathrm{C}$ e a velocidade do vento, de aproximadamente $2 \mathrm{~km} \mathrm{~h}^{-1}$. As folhas das plantas permaneceram 24 horas após a aplicação protegidas do contato com água da chuva ou proveniente da irrigação, visando evitar a lavagem do produto.

Imediatamente antes da aplicação foi coletada, por planta, uma folha totalmente expandida do terceiro nó, a partir do ápice caulinar, para o estudo histológico e histoquímico, sendo utilizadas seis plantas por espécie. Os testes para verificação da presença da cutícula, por meio do reagente Sudan III (Pearse, 1985), foram aplicados em cortes da região mediana e da margem da folha em amostras frescas seccionadas transversalmente em micrótomo de mesa (modelo LPC, Rolemberg e Bhering Comércio e Importação Ltda, Belo Horizonte, Brasil), sendo o laminário montado com gelatina glicerinada.

Para descrever os caracteres da superfície, fragmentos foliares, de aproximadamente
$1 \mathrm{~cm}^{2}$, provenientes da região mediana de cada folha coletada (um fragmento por planta), foram dissociados utilizando-se ácido nítrico e ácido crômico (Jensen, 1962). As amostras foram coradas com azul de astra e fucsina básica (Kraus et al., 1998), e as lâminas, montadas com gelatina glicerinada.

As determinações do tipo de estômato seguiram a classificação proposta por Metcalfe \& Chalk (1979). A análise e a documentação fotográfica do laminário histológico foram realizadas utilizando-se um microscópio fotônico (modelo AX70TRF, Olympus Optical, Tokyo, Japão) com sistema U-Photo.

Para determinação do índice estomático, densidade estomática (estômatos $\mathrm{mm}^{-2}$ ), densidade de células epidérmicas propriamente ditas (número de células $\mathrm{mm}^{-2}$ ) e densidade de cavidades (cavidades $\mathrm{mm}^{-2}$ - mensuradas conforme as células de cobertura na epiderme foliar), foram realizadas dez observações por planta para cada face epidérmica, em campos com área correspondente a $0,067 \mathrm{~mm}^{2}$. Os dados quantitativos da superfície epidérmica foram obtidos com auxílio do software ImagePro Plus. O cálculo do índice estomático foi feito de acordo com a fórmula de Cutter (1986): índice estomático $(\mathrm{IE})=[\mathrm{NE} /(\mathrm{CE}+\mathrm{NE})] \times 100$, em que $\mathrm{NE}$ é o número de estômatos e $\mathrm{CE}$ o número de células epidérmicas propriamente ditas.

Após a aplicação do herbicida foram observadas, diariamente, alterações morfológicas na parte aérea das plantas. Aos 45 dias após a aplicação (DAA) determinou-se a porcentagem de intoxicação em relação à testemunha, em que $0 \%$ corresponde à ausência de sintomas visíveis e 100\% à morte das plantas (Frans, 1972).

Os dados quantitativos foram submetidos à análise de variância e as médias comparadas a 5\% de probabilidade pelo teste de Tukey, utilizando-se o Aplicativo Computacional para Análises Genéticas e Estatísticas - GENES. Para os dados de porcentagem de intoxicação, foram ajustadas equações de regressão em função das subdoses de glyphosate aplicadas, simulando uma deriva.

\section{RESULTADOS E DISCUSSÃO}

As cinco espécies de Eucalyptus apresentam folhas glabras, anfiestomáticas, com 
estômatos do tipo anomocítico e dispostos no mesmo plano das demais células epidérmicas (Figura 1A-E). A epiderme é unisseriada e apresenta células com formato variando entre tabular e arredondado (Figura 1E), salvo nas regiões da nervura mediana e dos bordos foliares, onde as células são papilosas (Figuras $1 \mathrm{~F}$ e 2B). Lenticelas foram visualizadas na face abaxial da epiderme das cinco espécies. Nas cinco espécies, a cutícula é conspícua, sendo evidenciada pelo Sudam III (Figura 2).

Diferença significativa entre as espécies $(\mathrm{p}<0,05)$ foi encontrada para índice estomático (\%), densidade de estômatos (estômatos $\mathrm{mm}^{-2}$ ), densidade de cavidades (cavidades $\mathrm{mm}^{-2}$ ) e para densidade de células epidérmicas propriamente ditas (número de células epidérmicas propriamente ditas $\mathrm{mm}^{-2}$ ). Os valores médios e os respectivos testes de média para as variáveis quantitativas da superfície epidérmica encontram-se nas Figuras 3 a 6.

Cavidades estão dispersas no mesofilo e na nervura mediana das espécies de Eucalyptus estudadas, predominantemente localizadas na região subepidérmica das duas faces da folha (Figura 2A). As cavidades são identificadas na superfície epidérmica por duas células de cobertura (Figura 1C). E. pellita apresenta a maior densidade de cavidades, tanto na face abaxial quanto na adaxial da folha (Figura 5).
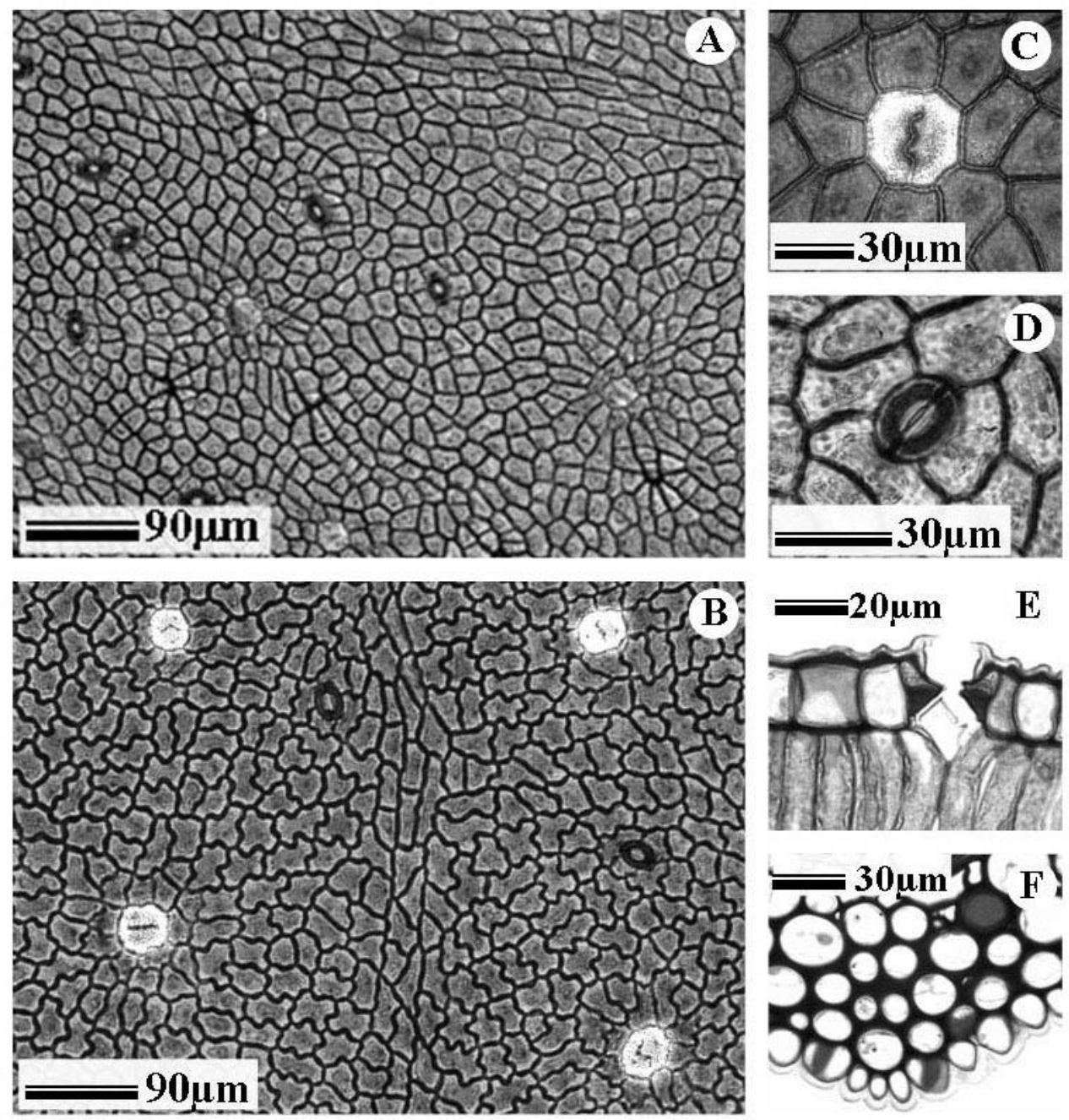

Figura 1 - A-D: vista frontal da face adaxial da epiderme da lâmina foliar de espécies de Eucalyptus - fragmentos submetidos à dissociação. A: E. grandis; B: E. resinifera; C: detalhe das duas células de cobertura da cavidade secretora de E. pellita; D: detalhe do estômato de E. pellita; E: secção transversal da lâmina foliar de E. pellita, evidenciando um estômato; F: células epidérmicas papilosas da região da nervura em secção transversal da lâmina foliar de E. grandis. 

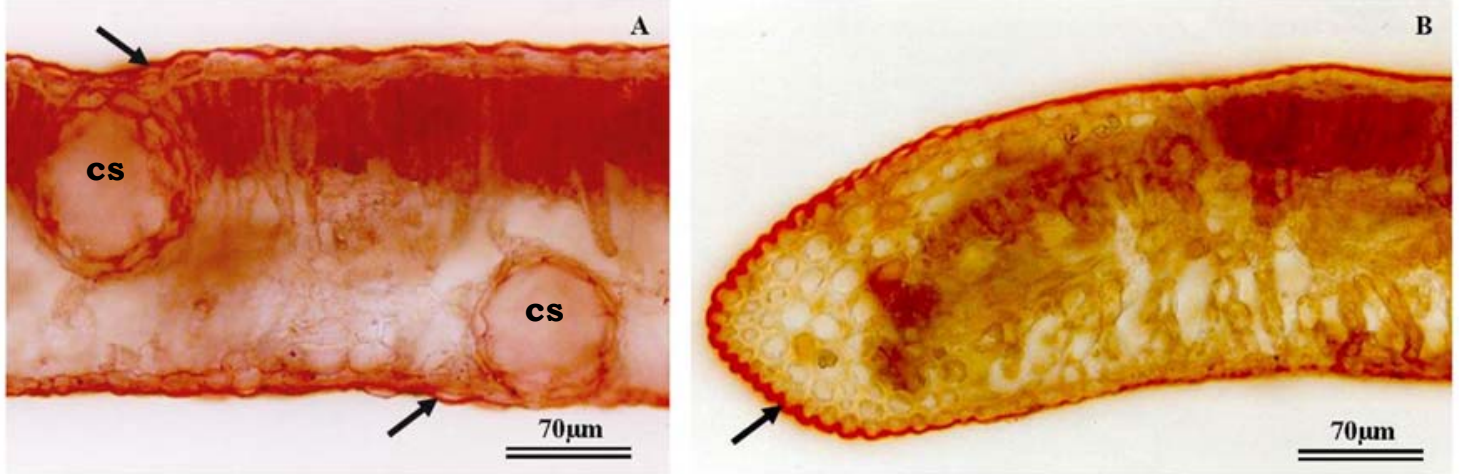

Figura 2 - Cortes transversais da lâmina foliar de espécies de Eucalyptus submetidas ao Sudam III. As setas mostram a cutícula foliar (cs - cavidade secretora); A - porção mediana de E. pellita; e B - margem de E. urophylla.

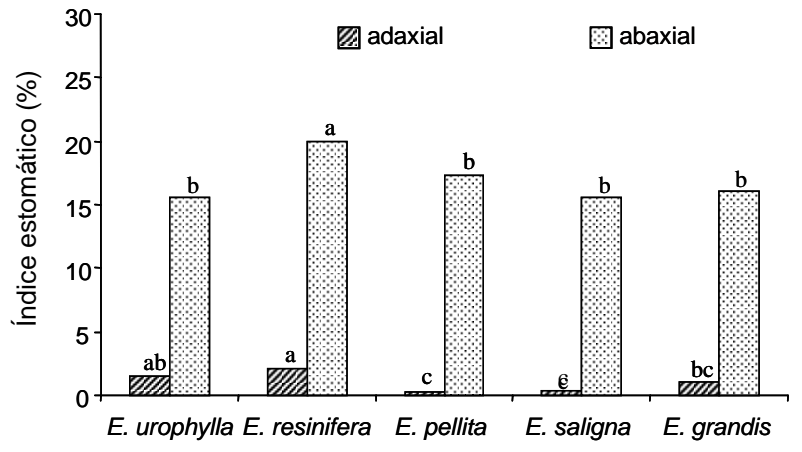

Médias seguidas pelas mesmas letras dentro da mesma face epidérmica não diferem entre si a $5 \%$ de probabilidade pelo teste de Tukey.

Figura 3 - Índice estomático de cinco espécies de Eucalyptus.

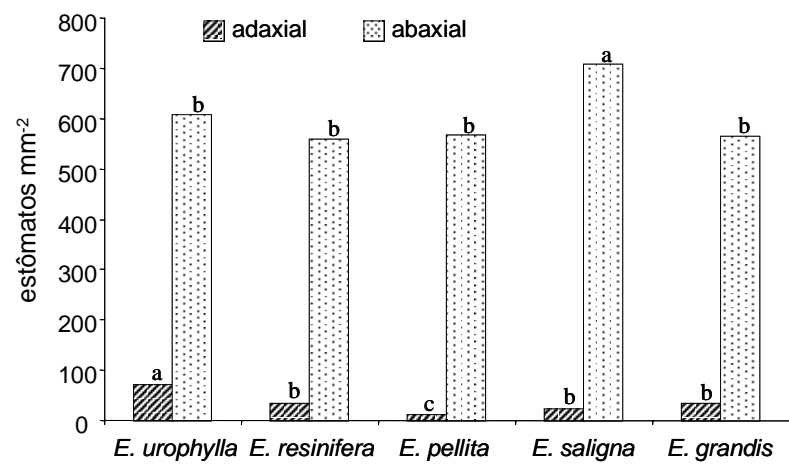

Médias seguidas pelas mesmas letras dentro da mesma face epidérmica não diferem entre si a $5 \%$ de probabilidade pelo teste de Tukey.

Figura 4 - Densidade estomática de cinco espécies de Eucalyptus.

A densidade de estômatos na superfície adaxial foi menor do que na abaxial (Figura 4), e a densidade de cavidades (Figura 5), em ambas as superfícies, foi notavelmente menor que a densidade de estômatos em todas as espécies estudadas. Resultados semelhantes foram obtidos por James \& Bell (1995) quando analisaram folhas de E.camaldulensis. A densidade estomática é variável de acordo com a idade da planta e diretamente influenciada pelas condições ambientais (Cao, 2000; Justo et al., 2005). Entretanto, esta característica está positivamente relacionada com a assimilação de $\mathrm{CO}_{2}$ (Abrams et al., 1994; Justo et al., 2005), provavelmente pela relação positiva da densidade estomática com as trocas gasosas (Araus et al., 1986) e com a maior condutância estomática (Boardman, 1977). Por outro lado, o índice estomático é um parâmetro relativamente constante para cada espécie (Cutter, 1986),

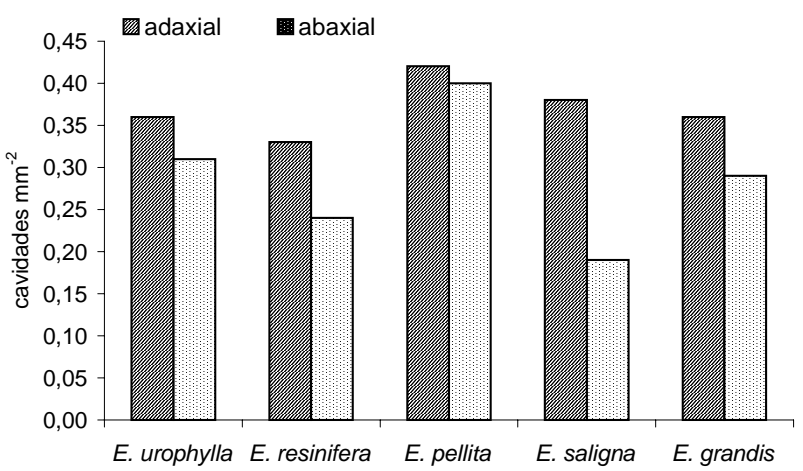

Médias seguidas pelas mesmas letras dentro da mesma face epidérmica não diferem entre si a 5\% de probabilidade pelo teste de Tukey.

Figura 5 - Densidade de cavidades vista por células de cobertura nas epidermes abaxial e adaxial de cinco espécies de Eucalyptus. 
tendo, portanto, maior relevância taxonômica. Tomando como base a face abaxial da epiderme, onde se concentra o maior número de estômatos, poderia se associar a maior densidade estomática de $E$. saligna a uma maior assimilação de $\mathrm{CO}_{2}$, quando comparada com as demais espécies.

Quanto à densidade de células epidérmicas propriamente ditas, E. saligna apresenta o maior número de células por área, tanto na face adaxial quanto na abaxial. Contrariamente, E. pellita e E. resinifera apresentam menor densidade de células epidérmicas (Figura 6). Visualmente, essa diferença é definida quando se comparam as espécies de maior com as de menor densidade de células epidérmicas (Figura 1A, B).

A intoxicação das plantas variou de acordo com as doses testadas $(\mathrm{p}<0,05)$ aos 45 dias após aplicação (DAA), sendo tanto maior quanto maiores as doses de glyphosate (Figura 7). Entretanto, houve variação entre as espécies $(\mathrm{p}<0,05)$ quanto à porcentagem de intoxicação das plantas, sendo a interação doses versus espécie não-significativa $(\mathrm{p}>0,05)$.

Nas cinco espécies estudadas verificou-se murcha, clorose e enrolamento das folhas dos ápices das plantas pulverizadas com as doses de 172,8 e $345,6 \mathrm{~g} \mathrm{ha}^{-1}$ e, em menor intensidade, para 86,4 $\mathrm{g} \mathrm{ha}^{-1}$ de glyphosate. Os sintomas eram visíveis a partir do $4^{\circ} \mathrm{DAA} \mathrm{em}$ E. grandis, E. pellita e E. urophylla e do 5 DAA em E. resinifera e E. saligna. Os sintomas nas

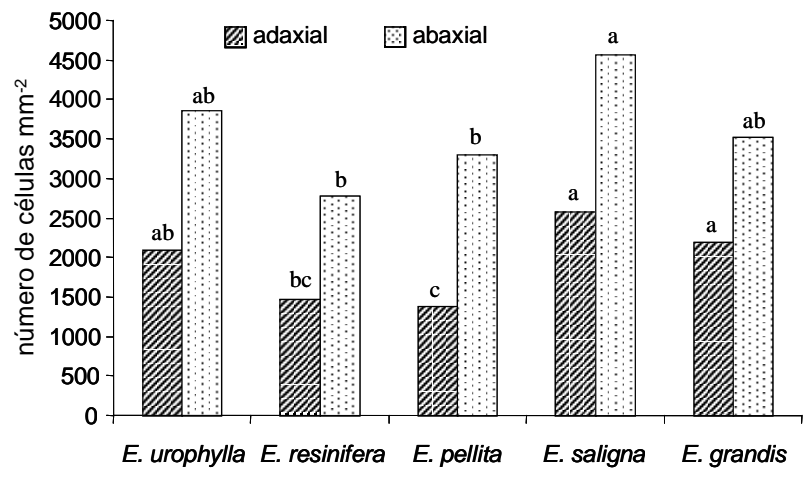

Médias seguidas pelas mesmas letras dentro da mesma face epidérmica não diferem entre si a 5\% de probabilidade pelo teste de Tukey.

Figura 6 - Densidade de células epidérmicas propriamente ditas nas faces abaxial e adaxial de cinco espécies de Eucalyptus. plantas que receberam as doses de $172,8 \mathrm{e}$ $345,6 \mathrm{~g} \mathrm{ha}^{-1}$ de glyphosate evoluíram para folhas coriáceas, ápices deformados, necroses bem desenvolvidas nos bordos das folhas e senescência foliar acentuada. Sintomas foliares semelhantes em plantas de eucalipto submetidas à deriva simulada com glyphosate foram relatados por Tuffi Santos et al. (2005, in press). A clorose pode ser resultado da degeneração dos cloroplastos (Campbell et al., 1976) e/ou da inibição da formação de clorofila (Cole et al., 1983) como resultado da ação do glyphosate em plantas.

As doses de 172,8 e $345,6 \mathrm{~g} \mathrm{ha}^{-1}$ de glyphosate provocaram a morte dos ápices das plantas, em E. grandis, E. urophylla, E. saligna e E. pellita; nestas espécies, a intoxicação das plantas alcançou valores superiores a $62 \%$ aos 45 DAA (Figura 7). Em E. resinifera não foi observada morte dos ápices das plantas, e nesta espécie ocorreram as menores notas de intoxicação, aproximadamente 50\% dos valores das demais espécies (Figura 7), mostrando-se, portanto, mais tolerante ao glyphosate. O comportamento diferencial entre os genótipos submetidos à deriva de glyphosate foi relatado por Tuffi Santos et al. (in press), em que o clone de $E$. grandis foi mais suscetivel ao herbicida que clones de $E$. urophylla e eucalipto urograndis.

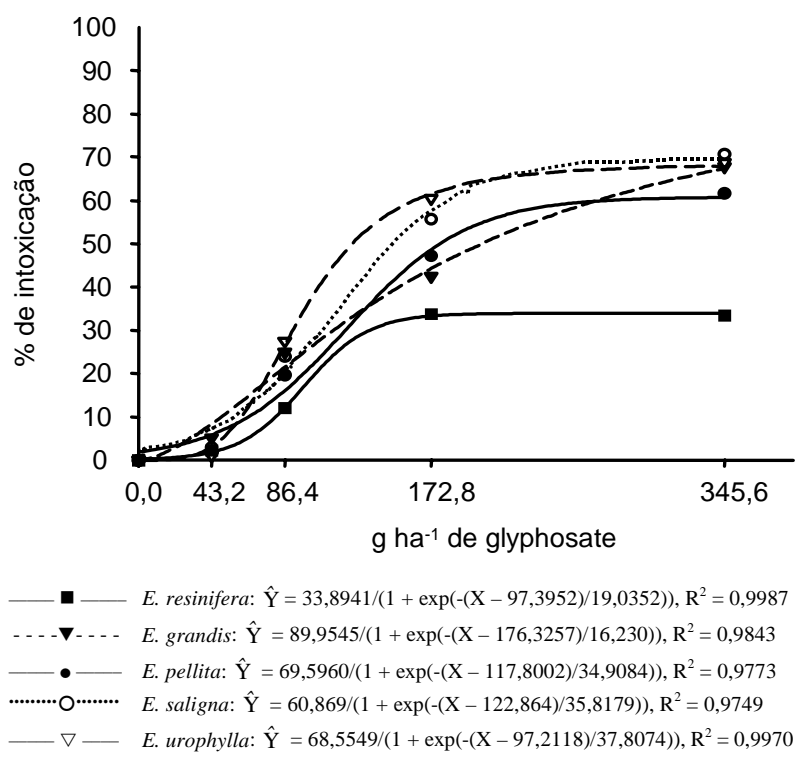

Figura 7 - Porcentagem de intoxicação de plantas de eucalipto submetidas à deriva simulada com glyphosate, 45 dias após aplicação. 
A correlação entre a porcentagem de intoxicação causada pelo glyphosate e as características índice estomático, densidade estomática e densidade de cavidades, nas duas faces epidérmicas das folhas de eucalipto, foi baixa e não-significativa ( $>0,05)$. Por sua vez, alta correlação positiva foi observada com a densidade de células epidérmicas propriamente ditas e com células epidérmicas totais da face adaxial das folhas (Tabela 1).

Tabela 1 - Correlações entre porcentagem de intoxicação de plantas submetidas à deriva de glyphosate e características da epiderme foliar de cinco espécies de eucalipto

\begin{tabular}{|c|c|}
\hline Característica epidérmica & $\begin{array}{l}\% \text { de intoxicação } \\
\text { por glyphosate }\end{array}$ \\
\hline Índice estomático EAB & $0,346^{\mathrm{ns}}$ \\
\hline Índice estomático EAD & $-0,036^{\text {ns }}$ \\
\hline Densidade de estômatos EAB & $0,445^{\text {ns }}$ \\
\hline Densidade de estômatos EAD & $-0,202^{\text {ns }}$ \\
\hline Densidade de cavidades EAB & $-0,284^{\text {ns }}$ \\
\hline Densidade de cavidades EAD & $0,089^{\mathrm{ns}}$ \\
\hline Densidade de células epidérmicas ${ }^{1 /}$ EAB & $0,552 *$ \\
\hline Densidade de células epidérmicas EAD & $0,896 * *$ \\
\hline Células totais ${ }^{2 /} \mathrm{EAB}$ & $0,432^{\text {ns }}$ \\
\hline Células totais EAD & $0,939 * *$ \\
\hline
\end{tabular}

1/ Células epidérmicas propriamente ditas. ${ }^{2 /}$ Somatório das células epidérmicas propriamente ditas + células estomáticas + células de cobertura das cavidades. $\mathrm{EAB}=$ face abaxial da epiderme; $\mathrm{EAD}=$ face adaxial da epiderme. ${ }^{\text {ns, } *} \mathrm{e} * *$ não-significativo e significativo a 5 e $1 \%$, respectivamente.

A cutícula foliar é a principal via de penetração do glyphosate, sendo a sua análise de importância fundamental nesses estudos (Devine, 1990). Nos estômatos, onde a cutícula sobre as células-guarda apresenta-se mais fina e mais permeável a substâncias polares (menor teor de cera epicuticular), parece ocorrer maior penetração de herbicidas (Hess \& Falk, 1990; Schreiber, 2005). Esse fato pode favorecer a penetração do glyphosate em plantas nas quais a presença de estômatos seja grande, principalmente na face adaxial da epiderme foliar, onde o contato com a calda herbicida aplicada é mais provável. Entretanto, nas folhas de eucalipto a baixa densidade de estômatos na face adaxial torna-se limitante para uma boa penetração do glyphosate por esta via (Tuffi Santos et al., in press), como pode ser confirmado pela baixa correlação encontrada neste estudo entre a porcentagem de intoxicação causada pelo glyphosate e o índice e densidade estomática de Eucalyptus.

Segundo Schönherr (2002), a presença de água é fundamental para uma boa penetração de glyphosate nas folhas, sendo evidente que grande parte do herbicida que penetra em seus tecidos passa por poros hidratados da cutícula. Estudos sobre a micromorfologia foliar de espécies do gênero Eucalyptus mostram que a superfície epidérmica é ondulada e a junção entre as células adjacentes apresenta-se em depressão (Louro et al., 1999; Tuffi Santos et al., in press). Tal fato pode predispor as regiões dos contornos celulares a uma maior hidratação e a um possível acúmulo da calda herbicida aplicada, favorecendo assim a absorção do glyphosate. Logo, maior densidade de células epidérmicas implicaria maior número de regiões mais propensas à penetração do glyphosate, o que explicaria a alta correlação positiva entre esta característica e a porcentagem de intoxicação causada por este herbicida em eucalipto. Contudo, estudos de absorção, translocação e metabolismo do glyphosate em eucalipto devem ser realizados para confirmação dos fenômenos envolvidos com a tolerância diferencial entre os genótipos desta espécie. Abordagens ultraestruturais também podem contribuir com informações sobre a estrutura da cutícula e da parede celular que podem se relacionar com a penetração diferencial do glyphosate.

\section{LITERATURA CITADA}

ABRAMS, M. D.; KUBISKE, M. E.; MOSTOLLER, S. A. Relating wet and dry year ecophysiology to leaf structure in contrasting temperate tree species. Ecology, v. 75, n. 1, p. 123-133, 1994.

ARAUS, J. L. et al. Relationship between photosynthetic capacity and leaf structure in several shade plants. Am. J. Bot., v. 76, n. 12, p. 1760-1770, 1986.

BAKER, E. A. Chemistry and morphology of plant epicuticular waxes. In: CUTLER, D. F.; ALVIN, K. L.; PRICE, C. E. (Ed.). The plant cuticle. London: Academic Press, 1982. p. 140-161.

BOARDMAN, N. K. Comparative photosynthesis of sun and shade plants. Ann. Rev. Plant Physiol., v. 28, p. 355-377, 1977. 
CAMPBELL, W. F.; EVANS, J. O.; REED, F. C. Effect of glyphosate on chloroplast ultrastructure of quack grass mesophyll cell. Weed Sci., v. 24, p. 22-25, 1976.

CAO, K. F. Leaf anatomy and chlorophhyll content of 12 woody species in contrasting light conditions in a Bornean heath forest. Can. J. Bot., v. 78, n. 10, p. 1245-1253, 2000.

COLE, D. J.; CASELEY, J. C.; DODGE, A. D. Influence of glyphosate on selected plant process. Weed Res., v. 23, p. 173-183, 1983.

CUTTER, E. G. Anatomia vegetal. Parte I - Células e tecidos. 2.ed. São Paulo: Roca, 1986. 304 p.

D'ANIERI, P. et al. Glyphosate translocation and efficacy relationships in red maple, sweet gum and loblolly pine seedlings. Forest Sci., v. 36, p. 438-447, 1990.

DEVINE, M. D. Mechanisms of herbicide absorption and translocation in plants. Weed Sci., v. 38, p. 279-285, 1990.

FRANS, R. E. Measuring plant responses. In: WILKINSON, R. E. (Ed.). Research methods in weed science. Australian: Southern Weed Science Society, 1972. p. 28-41.

HESS, F. D.; FALK, R. H. Herbicide deposition on leaf surfaces. Weed Sci., v. 38, n. 3, p. 280-288, 1990.

JAMES, S. A.; BELL, D. T. Morphology and anatomy of leaves of Eucalyptus camaldulensis clones: variation between geographically separated locations. Aust. J. Bot., v. 43, p. 415-433, 1995.

JENSEN, W. A. Botanical histochemistry: principles and practice. San Francisco: W. H. Freeman \& Co, 1962. 408 p.

JUSTO, C. F. et al. Plasticidade anatômica das folhas de Xylopia brasiliensis Sprengel (Annonaceae). Acta Bot. Bras., v. 19, p. 112-123, 2005.

KRAUS, J. E. et al. Astra blue and basic fuchsin double staining of plant materials. Biotech. Histochem., v. 73, p. 235-243, 1998.
LOURO, R. P.; SANTOS, A. V.; MACHADO, R. D. Ultrastructure of Eucalyptus grandis x E. urophylla I. shoots cultivated in vitro in multiplication and elongation-rooting media. Int. J. Plant Sci., v. 160, n. 2, p. 217-227, 1999.

MALIK, J.; BARRY, G.; KISHORE, G. The herbicide glyphosate. BioFactors, v. 2, p. 17-25, 1989.

METCALFE, C. R.; CHALK, L. Anatomy of the dicotyledons: systematic anatomy of leaf and stem, with a brief history of the subject. 2.ed. Oxford: Claredon Press, 1979. v. 2. 276 p.

MONQUERO, P. A. et al. Caracterização da superfície foliar e das ceras epicuticulares em Commelina benghalensis, Ipomoea grandifolia e Amaranthus hybridus. Planta Daninha, v. 22, n. 2, p. 203-210, 2004.

PEARSE, A. G. E. Histochemistry: theoretical and applied. 4.ed. London: Churchill Livingstone, 1985. v. 2. 1518 p.

SANDBERG, C. L.; MEGGITT, W. F.; PENNER, D. Absorption, translocation and metabolism of ${ }^{14} \mathrm{C}$-glyphosate in several weed species. Weed Res., v. 20, p. 195-200, 1980.

SATICHIVI, N. M. et al. Absorption and translocation of glyphosate isopropylamine and trimethysulfonium salts in Abutilon theophrasti and Setaria faberi. Weed Sci., v. 48, p. 675-679, 2000.

SCHÖNHERR, J. A mechanistic analysis of penetration of glyphosate salts across astomatous cuticular membranes. Pest Manag. Sci., v. 58, p. 343-351, 2002.

SCHREIBER, L. Polar paths of diffusion across plant cuticles: new evidence for an old hypothesis. Ann. Bot., v. 95, p. 1069-1073, 2005.

TOLEDO, R. E. B. et al. Faixas de controle de plantas daninhas e seus reflexos no crescimento de plantas de eucalipto. Sci. For., v. 64, p. 78-92, 2003.

TUFFI SANTOS, L. D. et al. Crescimento e morfoanatomia foliar de eucalipto sob efeito de deriva do glyphosate. Planta Daninha, v. 23, n. 1, p. 133-142, 2005.

TUFFI SANTOS, L. D. et al. Morphological responses of different eucalypt clones submitted to glyphosate drift.

Environ. Exp. Bot., (in press) 